\title{
Bicuspid aortic valve repair: systematic review on long-term outcomes
}

\author{
George J. Arnaoutakis ${ }^{1}$, Ibrahim Sultan ${ }^{2}$, Mary Siki $^{3}$, Joseph E. Bavaria ${ }^{3}$ \\ ${ }^{1}$ Division of Thoracic and Cardiovascular Surgery, University of Florida, Gainesville, Florida, USA; ${ }^{2}$ Department of Cardiothoracic Surgery, \\ University of Pittsburgh, Pittsburgh, Pennsylvania, USA; ${ }^{3}$ Division of Cardiovascular Surgery, University of Pennsylvania, Philadelphia, \\ Pennsylvania, USA \\ Correspondence to: George J. Arnaoutakis, MD. Assistant Professor of Surgery, Division of Thoracic and Cardiovascular Surgery, University of Florida, \\ 1505 SW Archer Rd., Gainesville, FL 32608, USA. Email: George.arnaoutakis@surgery.ufl.edu.
}

\begin{abstract}
Background: Many patients with bicuspid aortic valve (BAV) develop aortic regurgitation but are not considered for valve repair. This is partly due to limited long term data regarding repair durability. The purpose of the review is to summarize the long-term (1 year) outcomes of BAV repair.

Methods: A systematic review was performed to evaluate durability and survival following BAV repair. OVID SP versions of MEDLINE and Embase were searched using 'aortic valve', 'bicuspid', 'repair', 'David' 'Yacoub', 'reimplantation' and 'remodeling'.

Results: Initial search produced 770 abstracts, reduced to 92 full papers for review after excluding duplications and abstract review for relevance. Twenty-six studies met full inclusion criteria. BAV repair revealed low operative mortality, with excellent 5-year survival, and low freedom from reoperation. Differences in surgical technique between reimplantation and remodeling do not appear to confer protection against reintervention. Systematic assessment of cusp height and annular stabilization in some form do appear to favor improved long term durability. Leaflet calcification is associated with higher rates of reintervention.
\end{abstract}

Conclusions: BAV repair is associated with acceptable long term survival. Ongoing standardized outcome assessments will further refine surgical techniques associated with excellent repair durability.

Keywords: Bicuspid aortic valve (BAV); aortic valve repair; long term outcomes

Submitted Apr 01, 2019. Accepted for publication May 07, 2019.

doi: $10.21037 /$ acs.2019.05.08

View this article at: http://dx.doi.org/10.21037/acs.2019.05.08

\section{Introduction}

Bicuspid aortic valve (BAV) is seen in $1-2 \%$ of the general population and is one of the most common congenital abnormalities with a strong male preponderance (1). Some patients will develop valvular pathology in childhood, while most develop either aortic regurgitation or stenosis in adulthood up to the seventh decade in life. Severe aortic stenosis is typically managed with valve replacement, whereas patients with aortic regurgitation may be candidates for valve repair based on anatomic classification and functionality of the valve (2-5). However, a large majority of patients with aortic regurgitation undergo valve replacement because of concomitant stenosis or because of a valve that is not amenable to repair. Mechanical prostheses may predispose patients to higher rate of thromboembolic events whereas bioprostheses may increase risk of endocarditis and reintervention $(6,7)$. Valve repair in these patients is desirable to avoid the above-mentioned complications that are invariably associated with prosthetic aortic valves. Successful valve repair in patients with BAV typically requires cusp repair with concomitant annular stabilization using either reimplantation or remodeling techniques $(2,8,9)$. The purpose of this review is to summarize the long-term outcomes of BAV repair. The primary end point was survival and secondary end points included freedom 


\begin{tabular}{l} 
Table 1 Search terms used to conduct systematic review \\
\hline Search terms \\
Aortic valve \\
Aortic valve regurgitation \\
Aortic stenosis \\
Thoracic aortic aneurysm \\
Repair \\
Bicuspid valve \\
Reimplantation (David) \\
Remodeling (Yacoub) \\
Annuloplasty \\
Outcomes \\
Cardiac Surgical procedures
\end{tabular}

from moderate or greater aortic regurgitation and freedom from reintervention.

\section{Methods}

\section{Literature search strategy}

We conducted searches of the OVID SP versions of MEDLINE and EMBASE using terms for 'aortic valve', 'bicuspid', 'repair', and 'long term outcomes' separated by the Boolean operator 'AND' (Table 1). The search was performed with and without 'long-term' to ensure no manuscripts were missed. Reports with less than 5 patients were not used. The search on studies published between 1985-2019, and the search was conducted on February 1, 2019. Additional searches queried articles with search terms recognized aortic valve-sparing procedures utilizing reimplantation or remodeling ('David', 'reimplantation', 'remodeling' and 'Yacoub' procedures) as well as annuloplasty. This study was confined to publications reporting outcomes in English. Derived references and leading cardiothoracic and cardiovascular themed journals were manually searched for further articles. All relevant citations were compiled utilizing EndNote X9 (Clarivate Analytics, Philadelphia, PA, USA) and duplicates were removed.

\section{Eligibility criteria}

We included publications that describe outcomes of BAV repair procedures. For purposes of this review, manuscripts including thoracic aortic aneurysm replacement or aortic root operations were included if the patient's native valve was preserved. To assess long term outcomes, only studies reporting outcomes greater than five years were included. Titles and abstracts of selected studies were reviewed by one author (GJ Arnaoutakis) and secondarily reviewed by a second author (I Sultan). Studies focused on aortic valve replacement, lacking detailed outcomes on bicuspid versus tricuspid morphology, and meeting presentations were all excluded. We defined studies which consisted of a single group of patients as case series, and cohort studies comprised those studies comparing at least two different study groups. Complete manuscripts of all potentially relevant studies were obtained and those not satisfying eligibility criteria were excluded.

\section{Data extraction and critical appraisal}

In studies that included patients with both BAV and tricuspid valves, the data for BAV patients were isolated. All information was collected on a dedicated data form to optimize data management and analysis. For studies published from the same center care was taken during critical appraisal to exclude overlapping patients by selecting the most recent study.

\section{Statistical analysis}

We evaluated outcome reporting by determining the frequency of endpoints describing when they were measured. Consistent with prior studies when the time period during which the endpoint was measured was reported, the outcome reporting was deemed to high standard (10). Poor outcome reporting was considered when the time period during which the outcome occurred was not identified. Poor outcome reporting was defined as failure to specify the time period during which the outcome occurred (e.g., operative mortality, late death). Outcome assessment was classified according to three categories: (I) perioperative period; (II) late mortality and reintervention rates; (III) echocardiographic and functional results.

\section{Results}

\section{Quantity of evidence}

The search produced 770 overall abstracts. After eliminating 


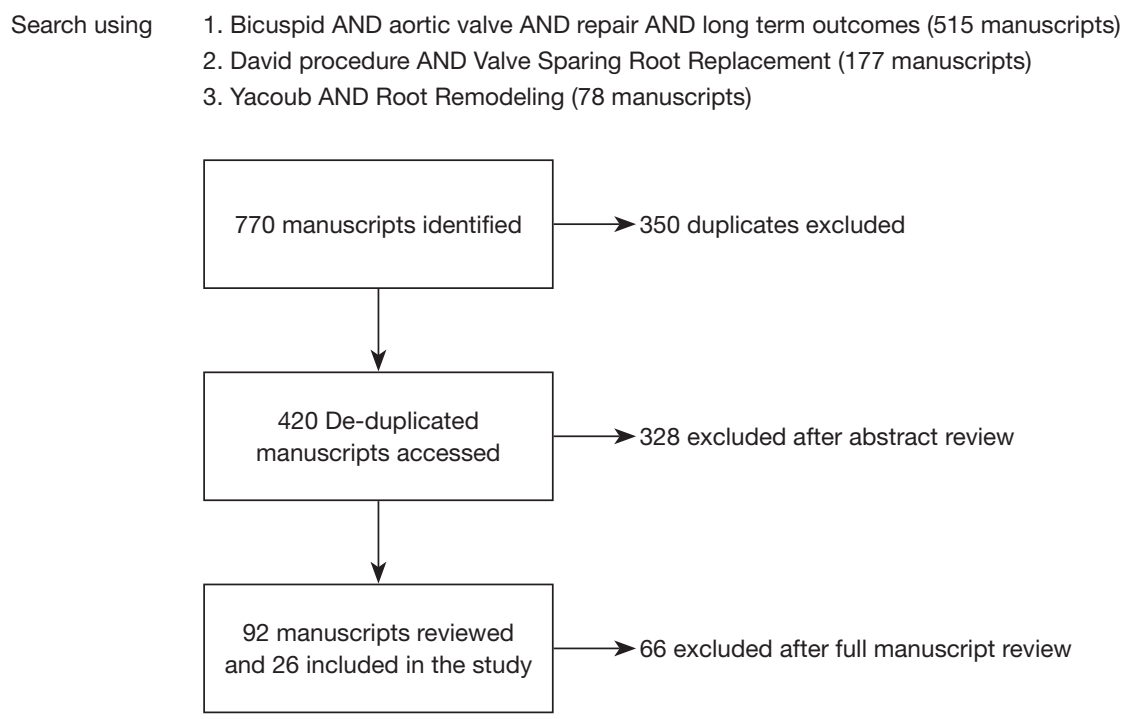

Figure 1 PRISMA diagram of studies considered for the systematic review.

duplicate records, 420 studies remained (Figure 1). Three hundred twenty-eight abstracts were excluded after review, with 92 manuscripts available for full review. Sixty-six manuscripts were eliminated, predominantly for lacking adequate long term reporting. Twenty-six studies were included in final review after eliminating (Table 2). These studies were published between 1999-2019. The majority of studies were retrospective $(\mathrm{n}=21)$, and some of these were case series. The majority of studies reported discrete time points for outcomes such as 30 day mortality, 1 year survival and freedom from reintervention.

\section{Remodeling}

Schneider $e t a l$. presented one of the largest series of BAV repair with root remodeling over a twenty-year period (8). Three hundred fifty-seven patients underwent cusp repair and 226 underwent concomitant suture annuloplasty. Fifteen-year survival was approximately $81 \%$ with $21.7 \%$ of patients requiring reoperation at 15 years. Calcification of the cusps and augmentation with pericardial patch were independently associated with risk of reoperation for recurrent aortic regurgitation (AR). Early on in their experience, isolated valve repair was performed without any annular support or stabilization that led to recurrent AR but with addition of suture annuloplasty like with other groups, freedom from AR increased in this cohort (35).

Lansac et al. reported their most recent data from AVIATOR (Aortic Valve repair InternATiOnal Registry) that underwent valve repair with remodeling and external aortic annuloplasty in 177 patients (28). Fifty-nine (33.6\%) patients had a BAV. These patients underwent valve repair using standardized approach using the remodeling technique, and effective height resuspension. Freedom from reintervention in the BAV cohort was $100 \%$ at 10 years with the use of external annuloplasty. Preoperative AR was the only predictor of recurrent AR in this series. Calibrated annuloplasty and effective height assessment were identified as protective factors from reoperation. The aortic ring used in the study was able to reduce the native annulus diameter by $4.3 \pm 3.9 \mathrm{~mm}$ thus providing an effective height of $10.2 \pm 3.3 \mathrm{~mm}(28)$.

\section{Reimplantation}

David and Feindel who initially described the reimplantation technique (VSRR) presented the longest available follow in this population that included 333 patients over a 20 year period (18). However, only $45(13.5 \%)$ patients had a BAV, $20 \%$ survival of the overall cohort was $72.4 \% \pm 3.8 \%$ at 20 years. Freedom from reoperation at 20 years was approximately $96 \%$ for the overall cohort with one bicuspid patient undergoing reoperation at eight years from index valve repair.

Kari et al. from Stanford University analyzed 75 BAV patients undergoing reimplantation technique for either AR (31\%) or root aneurysm (69\%) (25). Thirty-two percent had Sievers' type $0 \mathrm{BAV}$, with $66 \%$ receiving concomitant 
Table 2 Summary of major reports that present data on patients undergoing bicuspid aortic valve repair

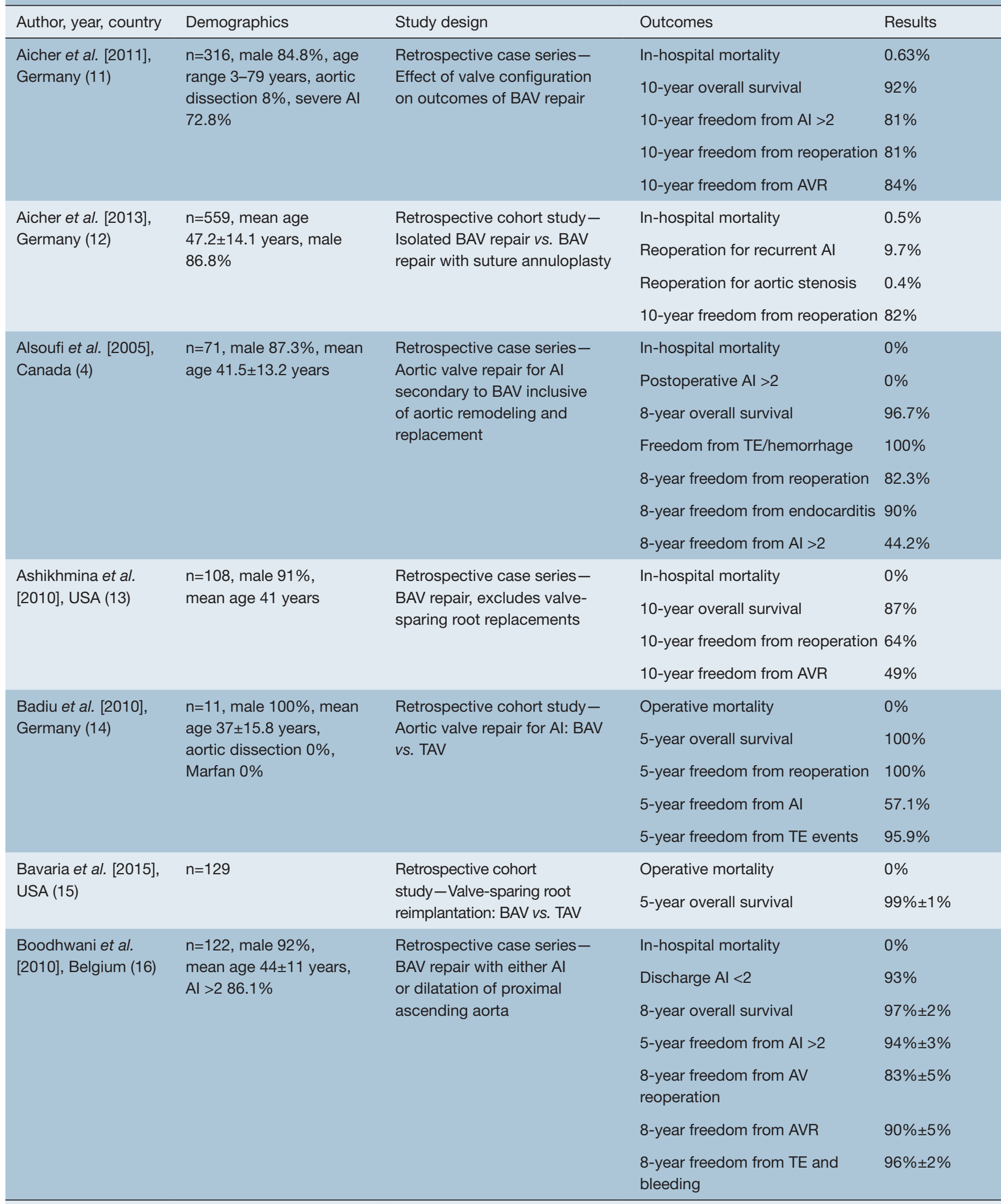

Table 2 (continued) 


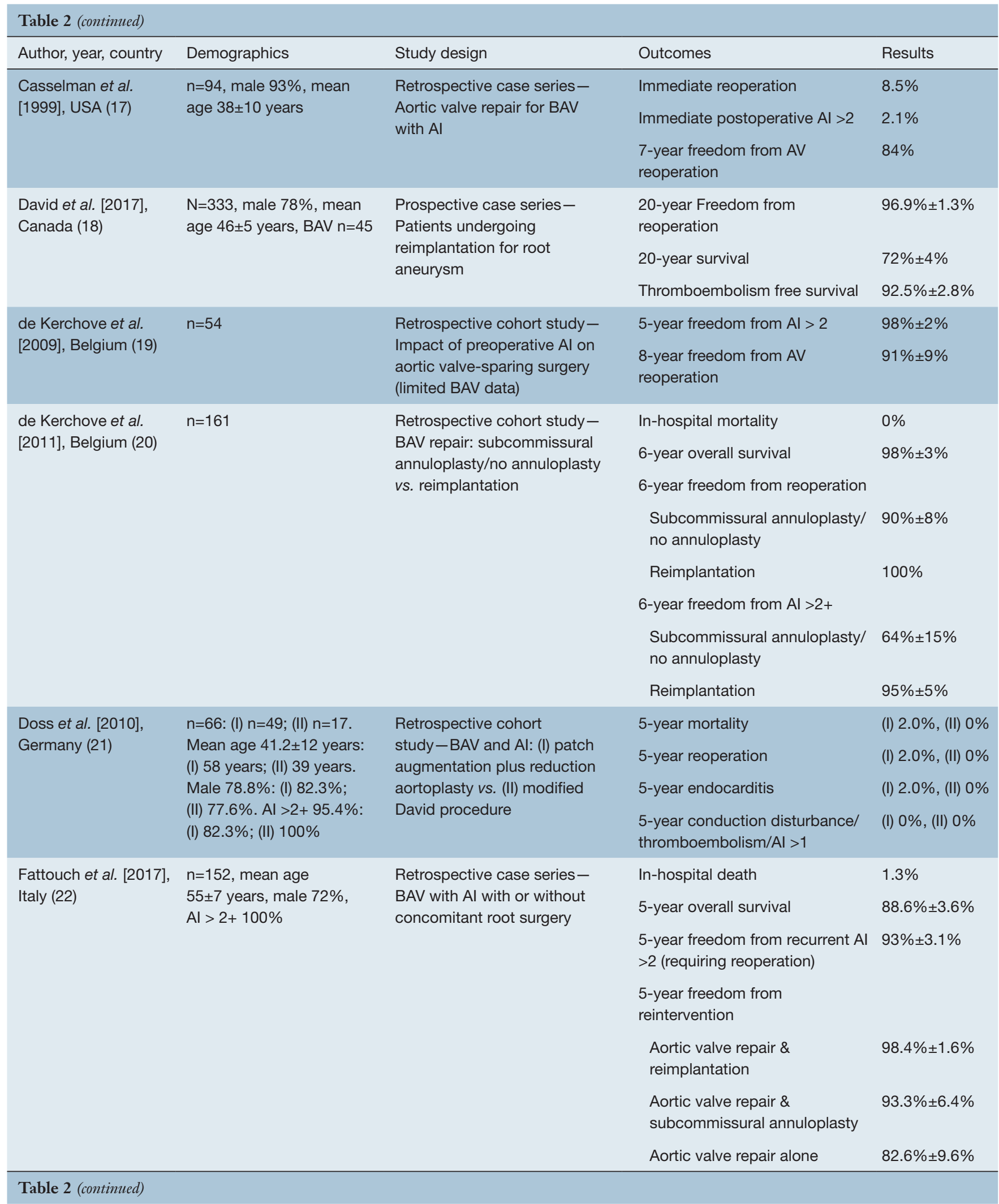


Table 2 (continued)

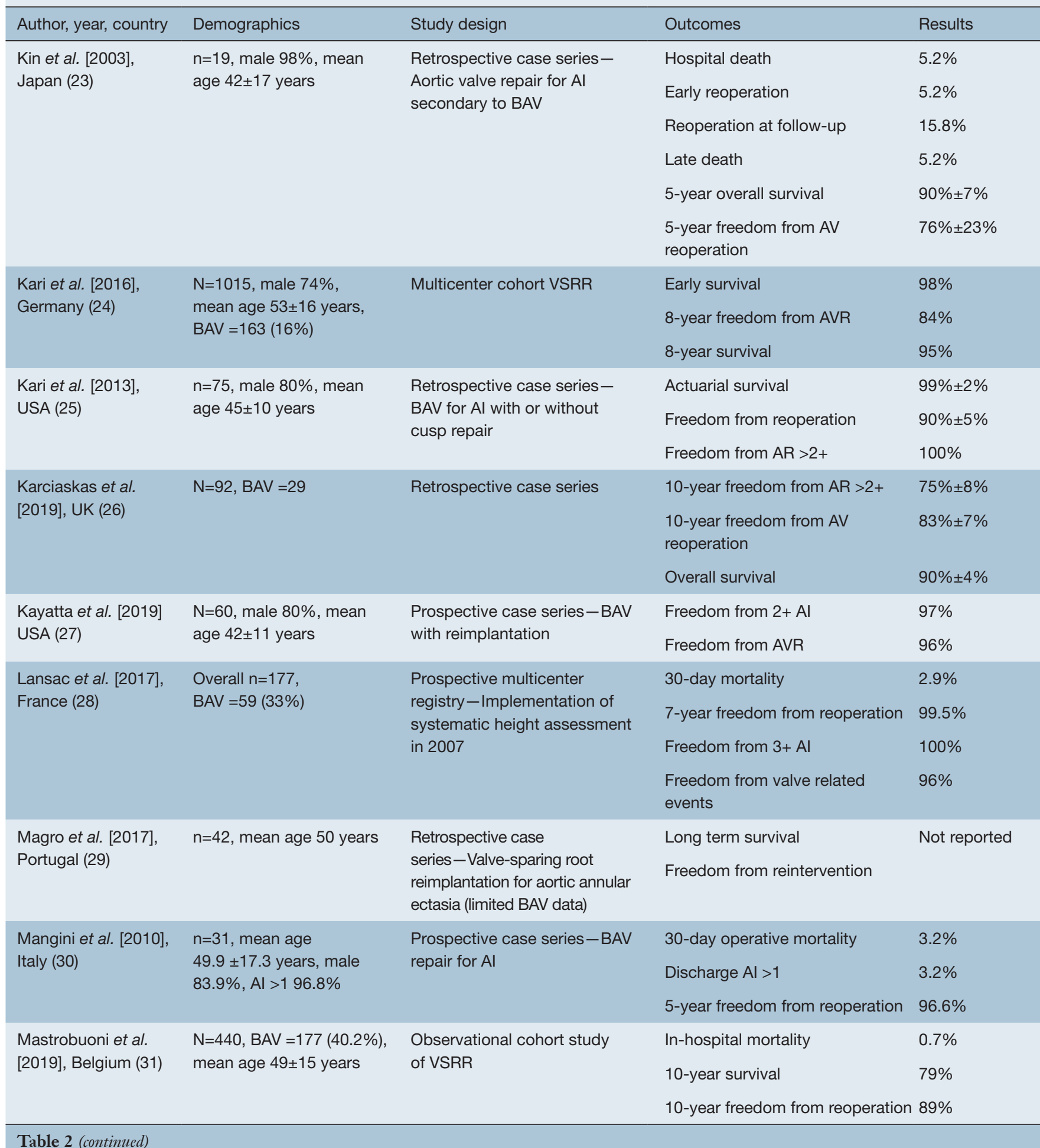

Table 2 (continued) 


\begin{tabular}{|c|c|c|c|c|}
\hline Author, year, country & Demographics & Study design & Outcomes & Results \\
\hline \multirow{3}{*}{$\begin{array}{l}\text { Miller [2015], } \\
\text { USA (32) }\end{array}$} & \multirow{3}{*}{$\begin{array}{l}\mathrm{n}=331, \text { Stanford } \\
\text { modification } 85.8 \% \text {, } \\
\text { Marfan } 38.4 \% \text {, } \\
\text { Loeys Dietz } 3.6 \%\end{array}$} & \multirow{3}{*}{$\begin{array}{l}\text { Retrospective case series- } \\
\text { Stanford modification } \\
\text { for valve-sparing root } \\
\text { replacement: BAV vs. TAV }\end{array}$} & Operative mortality & $0.6 \%$ \\
\hline & & & $\begin{array}{l}\text { 10-year freedom from AV } \\
\text { reoperation }\end{array}$ & $92 \% \pm 4 \%$ \\
\hline & & & $\begin{array}{l}10 \text {-year freedom from structural } \\
\text { valve deterioration }\end{array}$ & $96 \% \pm 2 \%$ \\
\hline \multirow{8}{*}{$\begin{array}{l}\text { Schafers et al. [2010], } \\
\text { Germany (33) }\end{array}$} & \multirow{8}{*}{$\begin{array}{l}\mathrm{n}=153, \text { mean age } \\
51 \pm 12 \text { years, male } 86.9 \% \text {, } \\
\text { preoperative Al grade } \\
2.6 \pm 0.8 \text {, aortic } \\
\text { dissection } 3.9 \%\end{array}$} & \multirow{8}{*}{$\begin{array}{l}\text { Retrospective case } \\
\text { series - Valve-sparing root } \\
\text { replacement for BAV and Al }\end{array}$} & In-hospital mortality & $0.7 \%$ \\
\hline & & & 10-year overall survival & $91 \%$ \\
\hline & & & 10-year freedom from $\mathrm{Al}>1$ & $90 \%$ \\
\hline & & & 10-year freedom from reoperation & $95 \%$ \\
\hline & & & 10-year freedom from AVR & $97 \%$ \\
\hline & & & TE events & $2.6 \%$ \\
\hline & & & Endocarditis & $0 \%$ \\
\hline & & & $\begin{array}{l}\text { 10-year freedom from AV } \\
\text { complications }\end{array}$ & $91 \%$ \\
\hline \multirow{5}{*}{$\begin{array}{l}\text { Schneider et al. } \\
\text { [2017], Germany (8) }\end{array}$} & \multirow{5}{*}{$\begin{array}{l}\mathrm{n}=357, \text { male } 90.8 \%, \\
\mathrm{Al} \geq 3+74.2 \%\end{array}$} & \multirow{5}{*}{$\begin{array}{l}\text { Retrospective case series- } \\
\text { Combined BAV repair and root } \\
\text { remodeling }\end{array}$} & In-hospital mortality & $0.6 \%$ \\
\hline & & & 15 -year overall survival & $81 \%$ \\
\hline & & & Reoperation for recurrent $\mathrm{Al}$ & $6.7 \%$ \\
\hline & & & Reoperation for aortic stenosis & $1.7 \%$ \\
\hline & & & $\begin{array}{l}15 \text {-year cumulative incidence of } \\
\text { reoperation }\end{array}$ & $21.7 \%$ \\
\hline \multirow{2}{*}{$\begin{array}{l}\text { Svensson et al. } \\
\text { [2014], USA (34) }\end{array}$} & \multirow{2}{*}{$\begin{array}{l}\mathrm{N}=728, \\
\text { mean age } 42 \pm 12 \text { years }\end{array}$} & \multirow{2}{*}{$\begin{array}{l}\text { Retrospective case series- } \\
\text { Combined BAV repair } \\
\text { techniques }\end{array}$} & 10-year freedom from reoperation & $78 \%$ \\
\hline & & & 10-year survival & $94 \%$ \\
\hline
\end{tabular}

BAV, bicuspid aortic valve.

cusp repair. At six years, survival was $99 \%$, and freedom from reoperation $90 \%$. Cusp free margin shortening was not associated with valve deterioration, but commissural suspensory neochord portended a higher probability of recurrent $\mathrm{AR}(\mathrm{P}=0.025)$.

De Kerchove et al. from Brussels have reported that the reimplantation technique with BAV repair has led to increase in repair rate and stabilization of the ventriculoaortic junction (VAJ). They studied 161 patients who underwent BAV repair from 1995 to 2010 (20). Eightyseven of these patients underwent BAV repair without reimplantation and 74 with reimplantation. There was no difference in survival between the two groups with 6-year overall survival $98 \%$. However, at 6 years freedom from $>2+\mathrm{AR}$ and reoperation were improved in the cohort undergoing concomitant reimplantation. A follow up study in 178 consecutive BAV patients divided BAV patients into three groups according to valve phenotype. Type A were patients who presented with symmetrical phenotype, type B were patients with asymmetrical phenotype and type $\mathrm{C}$ were patients with very asymmetrical phenotype which bordered on being similar to a tricuspid valve. Type $\mathrm{C}$ patients were more likely to have residual AR when compared to type A or B patients on discharge (36).

Bavaria et al. compared 186 patients with BAV undergoing VSRR to patients with tricuspid valves. There were no differences in baseline characteristics between either cohort. In the patients undergoing BAV repair, the transvalvular gradients were higher when compared to the tricuspid valve cohort at 1 year. There was no difference 
in postoperative $2+\mathrm{AR}$ and freedom from reoperation at 5 years (15). Follow up from the Penn group indicated that that VSRR was associated with improved durability in the setting of BAV. Patients who underwent subcommisural annuloplasty without annular support and an annular diameter greater than $30 \mathrm{~mm}$ were at higher risk for recurrent AR when compared to the VSRR group (37).

Esaki et al. examined risk factors for late aortic valve dysfunction after VSRR in a study including $64(22.7 \%$ of entire cohort) (38). There were 27 (9.6\%) overall reoperations and operative mortality $2.8 \%$. Forty-two (14.9\%) cases presented with acute aortic dissection. Seven-year cumulative incidence of reoperation, greater than $2+\mathrm{AI}$ and greater than moderate AS were $3.1 \%, 2.2 \%$, and $0.8 \%$, respectively. BAV and need for cusp repair were independent risk factors for late aortic stenosis greater than mild severity. A follow up study by Kayatta et al. from same institution reported 5-year freedom AVR 96\% (27).

\section{Remodeling $v s$. reimplantation}

Salcher $\mathrm{et}$ al. conducted a pooled analysis on the subject in 2016 with from 11 separate studies reporting on patients undergoing BAV repair (39). The mean age was 45.3 years with strong male preponderance $(82.1 \%)$. Less than half $(39.5 \%)$ of the patients underwent isolated BAV repair while $57.1 \%$ underwent aortic replacement with reimplantation or remodeling. Only $3.4 \%$ of the patients had connective tissue disorders. In hospital survival was greater than $99 \%$ and survival at 10 years was $91.2 \%$. Freedom from reintervention based on pooled analysis was $95.2 \%$ at 1 year and $80 \%$ at 10 years. Seven point five percent of patients underwent valve related intervention at a mean follow up of 3.9 years.

Rahnavardi et al. performed a 'best evidence review' to compare the ideal management strategy for annular support in patients undergoing aortic valve repair based on longevity of repair, freedom from AR and reoperation. In total, $10-15 \%$ of most series had patients with BAV. Both reimplantation and VSRR were used in BAV patients and there were no differences in freedom from reoperation when comparing either technique. More patients with BAV had undergone the remodeling technique. More patients had 2+ AR in the remodeling group; however, this did not result in greater need for reoperation. Finally, in patients with connective tissue disorders, acute aortic dissection and excessive annular dilatation, evidence appeared to favor VSRR over remodeling (40).

\section{Discussion}

Patients with BAV are prone to aortic stenosis, aortic regurgitation, ascending aortopathy, and infective endocarditis. The aims of surgery to correct these problems include restoration of normal valve function and replacement of the dilated ascending aorta and aortic root, when indicated. Surgical options include valve replacement with or without ascending replacement, composite aortic root replacement, Ross procedure, and aortic valve repair procedures. Aortic valve replacement is a time-tested excellent surgical option, however there are drawbacks to valve prostheses including anticoagulation for mechanical prostheses, bioprosthetic degeneration and risk of endocarditis. The impetus for development of aortic valve sparing procedures stemmed from these drawbacks and mirrored the surgical philosophy to reparative approaches to the mitral valve as espoused by Carpentier (41).

Because both perioperative and long term outcomes with aortic valve replacement are well established in the cardiac surgical literature, wide adoption of aortic valve repair in BAV patients will require techniques which are reproducible, safe, and durable. Prior systematic reviews have focused on outcomes with aortic valve repair procedures in BAV patients but have not exclusively focused on long term outcomes (10). Thus, the purpose of this systematic review was to evaluate published results on long term outcomes in patients undergoing BAV repair.

While there is no standardized definition for 'long term outcomes' we elected to include studies which reported outcomes that extended to at least five years. This decision is admittedly somewhat arbitrary, but provides a framework of reasonable duration follow up to provide a context for results that are less influenced by perioperative complications. While many studies report overall survival and freedom from reoperation, we believe it is also important to consider freedom from recurrent $>2+$ AR. Even if a patient is not undergoing reoperation, patients with $>2+$ AR may be undergoing more intensive surveillance regimens with frequent physician visits as well as suffering subclinical impact of longstanding moderate-severe AR, such as indolent adverse ventricular remodeling.

This systematic review has illuminated several technical points regarding determinants of long term success in BAV repair. First, while there are some conflicting reports, more recent studies indicate degree of preoperative AR does not seem to be associated with successful valve repair in the short or long term. Beckerman reviewed $60 \mathrm{BAV}$ patients 
undergoing VSRR and found that in their series $>50 \%$ of patients had preoperative moderate or worse AR, and freedom from $>2+$ AR at nine years was $97 \%$ (42).

$\mathrm{BAV}$ anatomy is variable as evidenced by the seminal anatomic description reported by Sievers (5). There are nuanced technical aspects of aortic valve repair that vary based on Sievers classification, especially given consideration to preserving cusp height, orientation, and symmetry. It was shown that commissural orientation was independently associated with risk for reoperation (11). Further, patients with very asymmetrical (120-139 degrees commissural orientation) were associated with greater need for aortic valve replacement and residual aortic regurgitation (36). There is theoretical concern that geometric orientation matters, because if not abiding by commissural alignment during repair there may be cusp distortion and stress, which may affect long term valve competence. However, if at the end of repair on intraoperative transesophageal echocardiography there is no residual AR, then it may be expected to lead to a durable valve repair. It has also been debated whether cusp fenestrations affect likelihood of a durable aortic valve repair. Small commissural fenestrations likely do not influence longevity of valve repair, although this has not been robustly studied in the literature. There is concern for overcorrecting valve pathology by aggressively addressing commissural fenestrations. If on baseline echocardiogram there is no AR emanating from commissural regions, it is likely safe not to address small commissural fenestrations.

Some authors have reported extensive leaflet debridement and patch repair for extensively calcified aortic cusps. Studies have shown however that need for aortic valve decalcification and patch repair portend poorer longevity of valve repair. In the era of transcatheter therapies, consideration should be given to valve replacement in these instances (8).

Annular diameter is an important consideration in BAV repair as many patients with bicuspid anatomy present with dilated aortic annulus (43). Therefore, patients with BAV experience good long term results with reimplantation technique, as this approach implicitly involves deep dissection to the level of the basal plane and annular reduction with placement of subannular sutures $(2,3)$. In the remodeling technique, addition of annuloplasty (whether internal or external) and systematic assessment of cusp effective height significantly improves durability $(43,44)$. There are numerous annuloplasty techniques described, and while the optimal annuloplasty technique has not been compared in randomized fashion, there are ample data from cohort studies to support routine use of annuloplasty in some fashion during remodeling procedures (45).

There is a stark difference in the number of unique centers with publications reporting long term outcomes greater than five years in BAV repair when compared to the number of centers whose reports are confined to perioperative and early outcomes. This highlights the relatively recent adoption of BAV repair techniques. The vast majority of experience with long term care of these patients is confined to relatively few centers worldwide. This is particularly the case in patients undergoing BAV repair in the setting of an aortic dissection where overall clinical status of the patient may play a large role in mortality and follow $(46,47)$. However, the dissemination of determinants of long term success in the form of systematic reviews and greater attention at national and international conferences are imperative in order to make these therapies available to a wider number of patients.

Enthusiasm for BAV repair techniques must also be considered in the context of the rapidly evolving technology in the form of transcatheter therapies. Newer generation surgical valve prostheses are being designed with future transcatheter valve-in-valve options in mind, to facilitate the subsequent procedures. It is likely that with the evolution of technology, patients in whom annuloplasty has been performed as part of BAV repair procedure may be candidates for transcatheter options in the future should recurrent isolated AR develop. This possibility makes BAV repair an even more attractive option at the outset, in order to lessen risks of infective endocarditis and anticoagulationrelated complications of mechanical prostheses.

\section{Limitations}

This review has several limitations. First, most studies were retrospective or observational. Second, surgeon decision regarding remodeling versus reimplantation, cusp repair and reimplantation techniques used were variable between centers. Third, there was no core/systematic echocardiography performed across centers which is the primary modality of looking for recurrent $\mathrm{AR}$ after valve repair which may affect interpretation of outcomes. Fourth, because of the paucity of data on the subject, this report did not lend itself to an appropriate or meaningful metaanalysis with cumulative statistical outcomes. Finally, there may be detection bias on our behalf and publication bias that may lead to incomplete reporting of results. 


\section{Conclusions}

This systematic review on long term outcomes following valve sparing surgery in patients afflicted with $B A V$ is effective and durable in the long term. However, the worldwide long term experience is confined to relatively few centers, and wider adoption of these techniques will likely grow with greater dissemination of established surgical principles in this patient population. Additional prospective observational studies, and ideally randomized trials, will be necessary to continue advancement of BAV repair procedures.

\section{Acknowledgments}

None.

\section{Footnote}

Conflicts of Interest: GJ Arnaoutakis-Consultant for Bolton Medical, Inc.; JE Bavaria-Research Grant, Edwards Lifesciences Corporation, Medtronic, Inc., COOK Medical, Boston Scientific, W.L. Gore \& Associates, St Jude Medical. The other authors have no conflicts of interest to declare.

\section{References}

1. Roberts WC. The congenitally bicuspid aortic valve. A study of 85 autopsy cases. Am J Cardiol 1970;26:72-83.

2. Sultan I, Komlo CM, Bavaria JE. How I Teach a Valve-Sparing Root Replacement. Ann Thorac Surg 2016;101:422-5.

3. El Khoury G, Vanoverschelde JL, Glineur D, et al. Repair of bicuspid aortic valves in patients with aortic regurgitation. Circulation 2006;114:I610-6.

4. Alsoufi B, Borger MA, Armstrong S, et al. Results of valve preservation and repair for bicuspid aortic valve insufficiency. J Heart Valve Dis 2005;14:752-8; discussion 758-9.

5. Sievers HH, Schmidtke C. A classification system for the bicuspid aortic valve from 304 surgical specimens. J Thorac Cardiovasc Surg 2007;133:1226-33.

6. Kilic A, Bianco V, Gleason TG, et al. Hospital readmission rates are similar between patients with mechanical versus bioprosthetic aortic valves. J Card Surg 2018;33:497-505.

7. Ouzounian M, Rao V, Manlhiot C, et al. Valve-Sparing Root Replacement Compared With Composite Valve Graft Procedures in Patients With Aortic Root Dilation. J Am Coll Cardiol 2016;68:1838-47.

8. Schneider U, Feldner SK, Hofmann C, et al. Two decades of experience with root remodeling and valve repair for bicuspid aortic valves. J Thorac Cardiovasc Surg 2017;153:S65-71.

9. Lansac E, de Kerchove L. Aortic valve repair techniques: state of the art. Eur J Cardiothorac Surg 2018;53:1101-7.

10. Vohra HA, Whistance RN, De Kerchove L, et al. Valvepreserving surgery on the bicuspid aortic valve. Eur J Cardiothorac Surg 2013;43:888-98.

11. Aicher D, Kunihara T, Abou Issa O, et al. Valve configuration determines long-term results after repair of the bicuspid aortic valve. Circulation 2011;123:178-85.

12. Aicher D, Bewarder M, Kindermann M, et al. Aortic valve function after bicuspidization of the unicuspid aortic valve. Ann Thorac Surg 2013;95:1545-50.

13. Ashikhmina E, Sundt TM 3rd, Dearani JA, et al. Repair of the bicuspid aortic valve: a viable alternative to replacement with a bioprosthesis. J Thorac Cardiovasc Surg 2010;139:1395-401.

14. Badiu CC, Eichinger W, Bleiziffer S, et al. Should root replacement with aortic valve-sparing be offered to patients with bicuspid valves or severe aortic regurgitation? Eur J Cardiothorac Surg 2010;38:515-22.

15. Bavaria JE, Desai N, Szeto WY, et al. Valve-sparing root reimplantation and leaflet repair in a bicuspid aortic valve: comparison with the 3-cusp David procedure. J Thorac Cardiovasc Surg 2015;149:S22-8.

16. Boodhwani M, de Kerchove L, Glineur D, et al. Repair of regurgitant bicuspid aortic valves: a systematic approach. J Thorac Cardiovasc Surg 2010;140:276-84.e1.

17. Casselman FP, Gillinov AM, Akhrass R, et al. Intermediate-term durability of bicuspid aortic valve repair for prolapsing leaflet. Eur J Cardiothorac Surg 1999;15:302-8.

18. David TE, David CM, Feindel CM, et al. Reimplantation of the aortic valve at 20 years. J Thorac Cardiovasc Surg 2017;153:232-8.

19. de Kerchove L, Boodhwani M, Glineur D, et al. Effects of preoperative aortic insufficiency on outcome after aortic valve-sparing surgery. Circulation 2009;120:S120-6.

20. de Kerchove L, Boodhwani M, Glineur D, et al. Valve sparing-root replacement with the reimplantation technique to increase the durability of bicuspid aortic valve repair. J Thorac Cardiovasc Surg 2011;142:1430-8.

21. Doss M, Risteski P, Sirat $S$, et al. Aortic root stability in bicuspid aortic valve disease: patch augmentation plus reduction aortoplasty versus modified David type repair. Eur J Cardiothorac Surg 2010;38:523-7.

22. Fattouch K, Moscarelli M, Castrovinci S, et al. Midterm results of bicuspid aortic valve repair guided by 
morphology and function assessment. Interact Cardiovasc Thorac Surg 2017;25:83-8.

23. Kin H, Izumoto H, Nakajima T, et al. Midterm results of conservative repair of the incompetent bicuspid aortic valve. J Cardiovasc Surg (Torino) 2003;44:19-23.

24. Kari FA, Doll KN, Hemmer W, et al. Survival and freedom from aortic valve-related reoperation after valvesparing aortic root replacement in 1015 patients. Interact Cardiovasc Thorac Surg 2016;22:431-8.

25. Kari FA, Liang DH, Kvitting JP, et al. Tirone David valve-sparing aortic root replacement and cusp repair for bicuspid aortic valve disease. J Thorac Cardiovasc Surg 2013;145:S35-40.e1-2.

26. Karciauskas D, Mizariene V, Jakuska P, et al. Early and long-term results of aortic valve sparing aortic root reimplantation surgery for bicuspid and tricuspid aortic valves. Perfusion 2019. [Epub ahead of print].

27. Kayatta MO, Leshnower BG, McPherson L, et al. ValveSparing Root Replacement Provides Excellent Midterm Outcomes for Bicuspid Valve Aortopathy. Ann Thorac Surg 2019;107:499-504.

28. Lansac E, Di Centa I, Sleilaty G, et al. Remodeling root repair with an external aortic ring annuloplasty. J Thorac Cardiovasc Surg 2017;153:1033-42.

29. Magro P, Marques M, Abecacis M. David Operation in the Bicuspid Aortic Valve Population. Rev Port Cir Cardiotorac Vasc 2017;24:131.

30. Mangini A, Lemma M, Contino M, et al. Bicuspid aortic valve: differences in the phenotypic continuum affect the repair technique. Eur J Cardiothorac Surg 2010;37:1015-20.

31. Mastrobuoni S, de Kerchove L, Navarra E, et al. Longterm experience with valve-sparing reimplantation technique for the treatment of aortic aneurysm and aortic regurgitation. J Thorac Cardiovasc Surg 2019. [Epub ahead of print].

32. Miller DC. Rationale and results of the Stanford modification of the David $\mathrm{V}$ reimplantation technique for valve-sparing aortic root replacement. J Thorac Cardiovasc Surg 2015;149:112-4.

33. Schafers HJ, Kunihara T, Fries P, et al. Valve-preserving root replacement in bicuspid aortic valves. J Thorac Cardiovasc Surg 2010;140:S36-40; discussion S45-51.

34. Svensson LG, Al Kindi AH, Vivacqua A, et al. Long-term durability of bicuspid aortic valve repair. Ann Thorac Surg 2014;97:1539-47; discussion 1548.

35. Aicher D, Schneider U, Schmied W, et al. Early results with annular support in reconstruction of the bicuspid aortic valve. J Thorac Cardiovasc Surg 2013;145:S30-4.
36. de Kerchove L, Mastrobuoni S, Froede L, et al. Variability of repairable bicuspid aortic valve phenotypes: towards an anatomical and repair-oriented classification. Eur J Cardiothorac Surg 2019. [Epub ahead of print].

37. Habertheuer A, Milewski RK, Bavaria JE, et al. Predictors of Recurrent Aortic Insufficiency in Type I Bicuspid Aortic Valve Repair. Ann Thorac Surg 2018;106:1316-24.

38. Esaki J, Leshnower BG, Binongo JN, et al. Risk Factors for Late Aortic Valve Dysfunction After the David V Valve-Sparing Root Replacement. Ann Thorac Surg 2017;104:1479-87.

39. Salcher M, Naci H, Pender S, et al. Bicuspid aortic valve disease: systematic review and meta-analysis of surgical aortic valve repair. Open Heart 2016;3:e000502.

40. Rahnavardi M, Yan TD, Bannon PG, et al. Aortic valvesparing operations in aortic root aneurysms: remodeling or reimplantation? Interact Cardiovasc Thorac Surg 2011;13:189-97.

41. Braunberger E, Deloche A, Berrebi A, et al. Very longterm results (more than 20 years) of valve repair with carpentier's techniques in nonrheumatic mitral valve insufficiency. Circulation 2001;104:I8-11.

42. Beckerman Z, Kayatta MO, McPherson L, et al. Bicuspid aortic valve repair in the setting of severe aortic insufficiency. J Vis Surg 2018;4:101.

43. Schneider U, Hofmann C, Aicher D, et al. Suture Annuloplasty Significantly Improves the Durability of Bicuspid Aortic Valve Repair. Ann Thorac Surg 2017;103:504-10.

44. Lansac E, Di Centa I, Sleilaty G, et al. Long-term results of external aortic ring annuloplasty for aortic valve repair. Eur J Cardiothorac Surg 2016;50:350-60.

45. Mazzitelli D, Pfeiffer S, Rankin JS, et al. A Regulated Trial of Bicuspid Aortic Valve Repair Supported by Geometric Ring Annuloplasty. Ann Thorac Surg 2015;99:2010-6.

46. Sultan I, McGarvey J, Vallabhajosyula P, et al. Routine use of hemiarch during acute type A aortic dissection repair. Ann Cardiothorac Surg 2016;5:245-7.

47. Vallabhajosyula P, Gottret JP, Menon R, et al. Central Repair With Antegrade TEVAR for Malperfusion Syndromes in Acute Debakey I Aortic Dissection. Ann Thorac Surg 2017;103:748-55.

Cite this article as: Arnaoutakis GJ, Sultan I, Siki M, Bavaria JE. Bicuspid aortic valve repair: systematic review on longterm outcomes. Ann Cardiothorac Surg 2019;8(3):302-312. doi 10.21037/acs.2019.05.08 